University of Nebraska - Lincoln

DigitalCommons@University of Nebraska - Lincoln

Faculty Publications, UNL Libraries

Libraries at University of Nebraska-Lincoln

February 1972

Dark Adaptation in the Presence of Waning Background

Luminances

Lothar Spillmann

Anne T. Nowlan

Charles D. Bernholz

cbernholz2@unl.edu

Follow this and additional works at: https://digitalcommons.unl.edu/libraryscience

Part of the Library and Information Science Commons

Spillmann, Lothar; Nowlan, Anne T.; and Bernholz, Charles D., "Dark Adaptation in the Presence of Waning Background Luminances" (1972). Faculty Publications, UNL Libraries. 20.

https://digitalcommons.unl.edu/libraryscience/20

This Article is brought to you for free and open access by the Libraries at University of Nebraska-Lincoln at DigitalCommons@University of Nebraska - Lincoln. It has been accepted for inclusion in Faculty Publications, UNL Libraries by an authorized administrator of DigitalCommons@University of Nebraska - Lincoln. 


\title{
Dark Adaptation in the Presence of Waning Background Luminances*
}

\author{
Lothar Spillmann, anne T. Nowlan, $\dagger$ and Charles D. Bernholz $\dagger$ \\ Department of Retina Research, Relina Foundation and Retina Service Laboratory, \\ Massachusetts Eye and Ear Infirmary, Boston, Massachusetts $\ddagger$
}

(Received 8 October 1970)

\begin{abstract}
The course of dark adaptation following low-level pre-exposure was determined against backgrouud luminances whose logarithms decreased linearly with time. Luminance was reduced by $7 \log$ units over periods of $3.5,7,14$, and 21 min. Transient adapting fields of this kind yield curves that remain increasingly behind the time course of normal dark thresholds; the delay varies with the rate of background change. Increment thresholds derived from such dark-adaptation curves exceed corresponding thresholds for stationary adapting fields by as much as $1.25 \mathrm{log}$ unit, particularly during the scotopic portion of steep luminance descents. The deficit in contrast sensitivity may be attributed to the additive action of the real background plus the equivalent background resulting from the pre-exposure bleach. Dark thresholds measured during temporary removal of a gradually decreasing field luminance are persistently elevated. This suggests that prolonged exposure to waning illumination may slow dark adaptation below its maximum rate.
\end{abstract}

InDEx HEADING: Vision.

Dark adaptation of the human eye is usually measured in complete darkness after pre-exposure to light. There are few studies ${ }^{1-8}$ in which the increase of sensitivity was determined in the presence of one or a series of adapting fields. Introduction of such fields not only restricts dark adaptation to the increment threshold for the lowest prevailing luminance, but also delays scotopic adaptation. At higher levels, backgrounds eventually shift the time of the cone break and even affect photopic thresholds. Consecutive exposure to a sequence of descending luminance steps, therefore, is not equivalent to continuous adaptation in the dark. If, instead of stationary backgrounds, flashes variable in luminance, duration, and number are interspersed at different times after pre-exposure, recovery from momentary threshold elevation is fast, with little if any permanent effects on subsequent adaptation. ${ }^{9-14}$

Large abrupt changes from light to darkness, commonly used in laboratory studies, hardly ever occur in nature. They may be considered as abnormal stimulus conditions if they exceed the instantaneous sensitivity gain afforded by the dilation of the pupil and by early cone adaptation. ${ }^{6}$ In this experiment, dark adaptation was measured against graded backgrounds whose range and rates of change were more compatible with the decline of natural illumination as, for example, at sunset.

The global luminance of the sky decreases over almost $7 \log$ units (with a constant rate of change of log luminance from $10^{2}$ to $10^{-3} \mathrm{~mL}$ ) as the sun travels from approximately $5^{\circ}$ above to $15^{\circ}$ below the horizon. ${ }^{15,16}$ During this period, the eye has to increase its sensitivity by a factor of more than a million, to maintain its optimum performance in spite of greatly varying luminance levels. In nature the corresponding change of threshold takes place over a period of $1.5-2 \mathrm{~h}$ as compared with 15-45 min under the usual laboratory conditions. Thus, by experimental standards, adaptation to the dark can proceed faster than is required by the rate of darkening in a natural environment. The question arises whether a gradually decreasing background delays dark adaptation and in what manner.

Hardly any data pertinent to this problem can be found in the literature. In a study of night flying, BeebeCenter, Carmichael, and Mead ${ }^{15}$ suggested that during twilight the eye adapts fast enough to keep up with the fall of environmental illumination. However, Allen and Carter, ${ }^{17}$ investigating traffic visibility in the mesopic and scotopic range, proposed that the state of adaptation of the eye lags behind the change of illumination that occurs after sunset. Neither opinion is supported by observational evidence.

In approaching this problem, three types of delayed dark adaptation ought to be distinguished. The first one is related to the difference in time or value between regular dark thresholds and increment thresholds determined upon a graded background. The second delay refers to the difference between increment thresholds measured against fixed and waning backgrounds of equal luminances. The third delay is defined by the difference between dark thresholds recorded after preexposure only or during short periods of intermittent extinction of a transient adapting field. All three delays are discussed with the rate of background change as the parameter. Tungsten light was used throughout the experiment eliminating possible favorable effects on rod threshold kinetics that might result from the reddening of the sky during evening hours.

\section{METHOD}

\section{Subject}

One of the authors, ATN, served as observer.

\section{Apparatus}

A three-channel visual discriminometer ${ }^{18}$ was employed for threshold measurements. One channel provided the stimulus, a $1^{\circ}$ white square presented for $0.04 \mathrm{~s}$ at $10^{\circ}$ from the center on the horizontal meridian in the nasal field. The second channel furnished a circular back- 


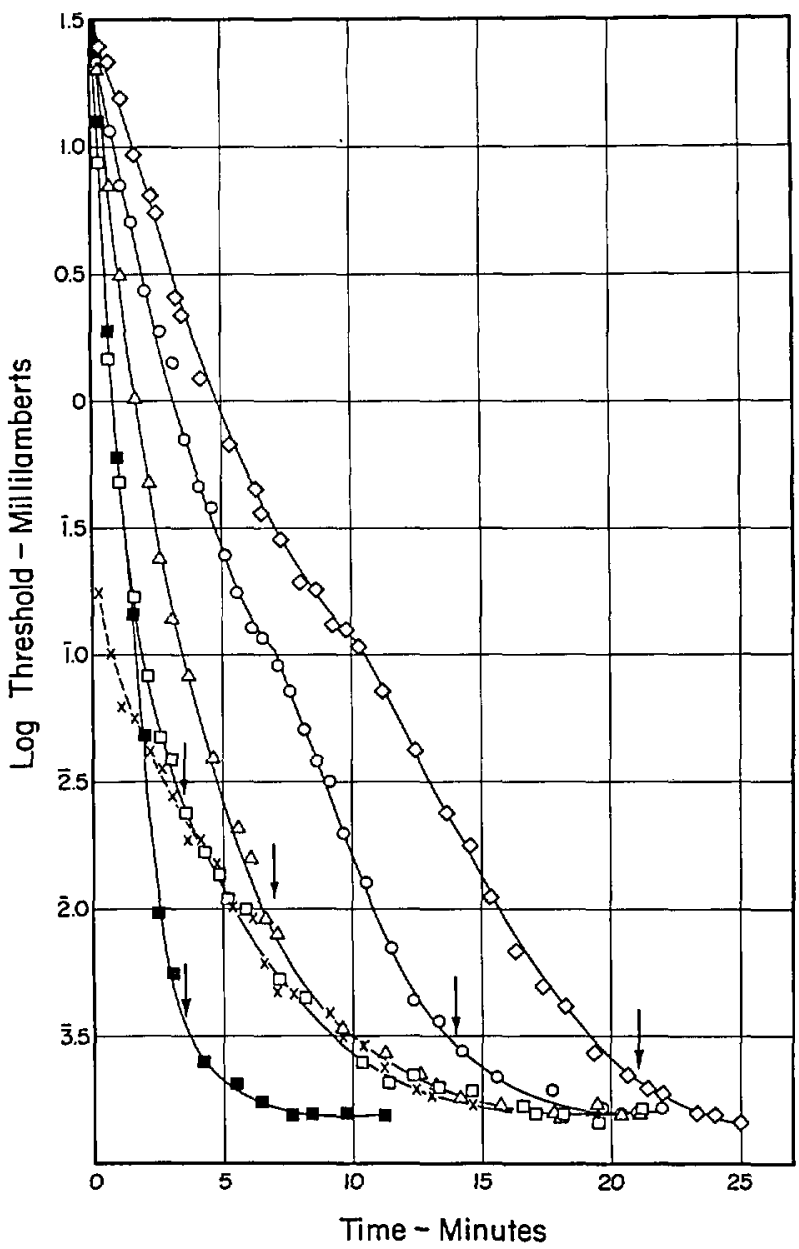

FIG. 1. Increment thresholds measured against log background luminance decreasing linearly with time. Backgrounds changed over $7 \log$ units within $3.5 \mathrm{~min}(\square), 7 \mathrm{~min}(\triangle), 14 \mathrm{~min}(O)$, $21 \mathrm{~min}(\diamond)$, and $3.5 \mathrm{~min}$ with no pre-exposure (a). Arrows indicate times of background extinction. Normal dark thresholds recorded in the absence of any background luminance $(x)$ largely coincide with the curve for the steepest background slope and are omitted after becoming invariant.

ground of $30^{\circ}$ angular subtense and was also used for pre-exposure. Through the third channel, a small red fixation mark was superimposed onto the field. The whole stimulus arrangement was seen in maxwellian view with an effective pupil of $1.5-\mathrm{mm}$ diameter. All observations were made from inside a light-proof booth built around the head of the discriminometer. A chinforehead rest was used to assure proper positioning.

\section{Procedure}

Thresholds were determined by use of the method of limits combined with preset stimulus luminances. Measurements were preceded by $45 \mathrm{~min}$ of dark adaptation followed (except where noted) by 5 -min preexposure to $325 \mathrm{~mL}$. Five procedures were used. (1) Adaptation in complete darkness. Thresholds were taken for a period of $21 \mathrm{~min}$. Four curves were recorded.
(2) Dark adaptation to a waning background. From the level of pre-exposure log background luminance was gradually reduced, at a constant rate, to a value of 3.25 $\times 10^{-5} \mathrm{~mL}$ by a second experimenter. The total change was completed within $3.5,7,14$, and $21 \mathrm{~min}$; at the end of these periods background luminance was set at zero. After the initial bleach, thresholds were measured for a duration of $21 \mathrm{~min}$ or longer until a level had been reached. Three runs for each rate of background change were made in a random order. (3) Dark adaptation to a waning background without previous pre-exposure. Beginning with a background of $325 \mathrm{~mL}$, the $\log$ of the adapting luminance was linearly and continuously reduced over $7 \mathrm{log}$ units within $3.5 \mathrm{~min}$. Results from four runs were obtained. (4) $\log \Delta I$ vs $\log I$ function. Increment thresholds were determined for the same range of backgrounds as above, presented in successive steps of 0.2 to $0.5 \mathrm{log}$ unit. To reach a steady state, the observer adapted for $90 \mathrm{~s}$ to each luminance level. Thresholds were established four times in ascending and descending order. (5) Instantaneous adaptation to complete darkness after intermittent extinction of a waning background. Dark thresholds were obtained while the adapting luminance, changing over periods of 14 and $21 \mathrm{~min}$, was temporally blocked by a cardboard inserted

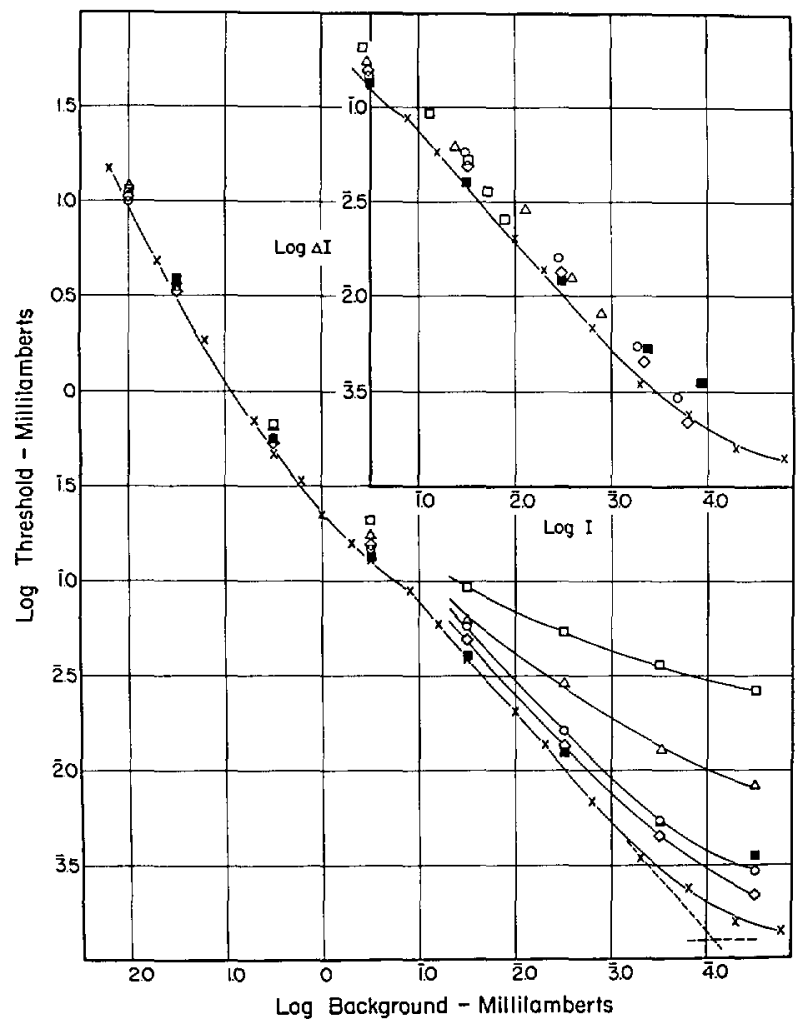

FIG. 2. Increment thresholds vs background luminance obtained under stationary $(x)$ and dynamic conditions (other symbols, same as in Fig. 1) for various rates of background change. The intersection of the broken lines denotes the value of Eigenlicht. Inset: Increment thresholds are replotted against the $\log$ of the sum of real and equivalent backgrounds. 
in to the light path. These dark intervals lasted from 15 to $90 \mathrm{~s}$, and one to three threshold measurements were made while the invisible background continued to decrease at a constant rate. Before and after each extinction, increment thresholds were measured as described under (2). Three runs were completed for both rates of luminance change.

\section{RESULTS}

Average thresholds were obtained by pooling individual measurements from the various runs within half-minute or, after $10 \mathrm{~min}$, full-minute intervals. Mean dark-adaptation curves for the experimental conditions (1)-(3) are presented in Fig. 1. After termination of pre-exposure, the threshold in complete darkness fell from $1.50 \log \mathrm{mL}$ (steady state) almost instantaneously by as much as $2.25 \log$ units before entering the measured portion of the dark-adaptation curve $(x)$. The curve does not appear to have a cone break but decreases smoothly for $2 \mathrm{log}$ units and reaches a plateau after $15 \mathrm{~min}$. For purposes of clarity, threshold values for the last $6 \mathrm{~min}$ are omitted from the graph.

In comparison, curves obtained in the presence of a waning background decrease gradually from the starting value through $4.0 \mathrm{log}$ units until they approach the final scotopic level. Their slopes vary according to the rate of background change. Only the curve representing the shortest background duration of $\mathbf{3 . 5} \mathrm{min}$ coincides in its lower portion with the course of normal dark adaptation. Thresholds measured against more slowly changing field luminances are increasingly displaced to the right and reach their end levels progressively later. For backgrounds descending over 14 and $21 \mathrm{~min}$, curves show a discontinuity at a threshold value of $0.1 \mathrm{~mL}$, which may be indicative of the cone break.

Adaptation to the fastest-changing field luminance recorded without pre-exposure proceeds almost linearly from the beginning to the end and overtakes ordinary dark thresholds after 2 min.

Figure 2 depicts the $\Delta I$ vs $I$ curve for stationary adapting fields, compared to increment thresholds measured against decreasing backgrounds. Thresholds for transient field luminances were derived from Fig. 1 after converting time on the abscissa into the background iuminances presented at given moments. Resulting values were plotted, decreasing toward the right, to indicate the sequence in which they were obtained in the experiment. Through most of the photopic range, increment thresholds for steady and transient backgrounds run close together, the second group being slightly elevated. Beginning at a luminance of about $0.3 \mathrm{~mL}$, however, the waning backgrounds yield considerably higher readings than measurements for steady state. This difference of threshold rapidly becomes greater with decreasing background luminance and increasing rate of change. A maximum threshold elevation of $1.25 \mathrm{log}$ unit is found when the adapting

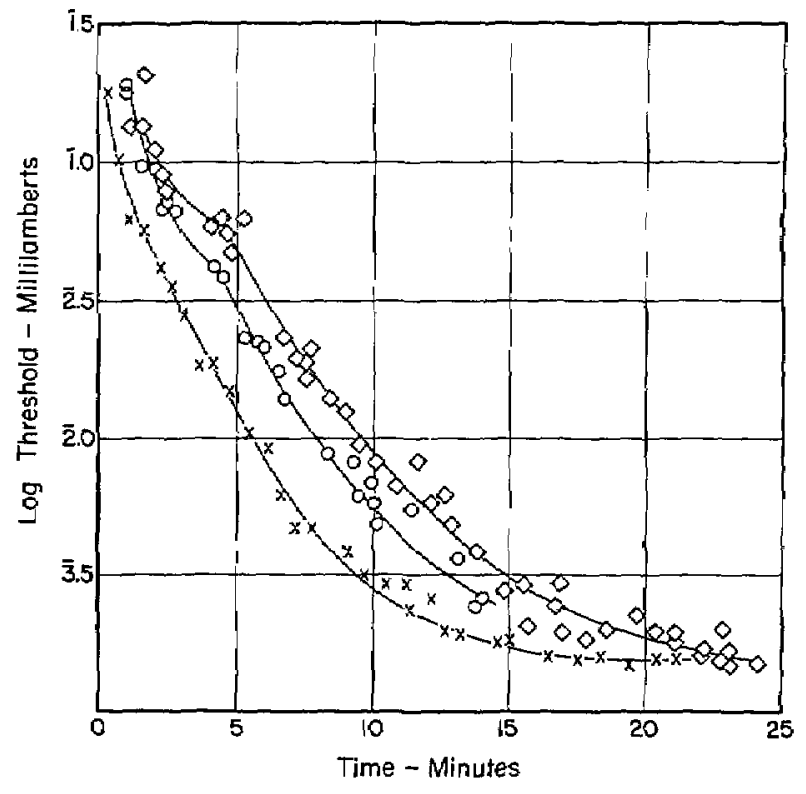

Fic. 3. Dark thresholds determined after pre-exposure only $(x)$ and during temporary extinction of background luminances decreasing over pericds of $14 \mathrm{~min}(\mathrm{O})$ and $21 \mathrm{~min}(6)$. Values for transient backgrounds were pooled from 3 runs each.

field assumes its minimum value $3.5 \mathrm{~min}$ after preexposure. In contrast, a deviation as small as $0.2 \log$ unit is measured when the same low background is presented after $21 \mathrm{~min}$. Threshold differences for the other curves referring to intermediate rates of change are between these two extremes. With a waning background lasting $3.5 \mathrm{~min}$, but no pre-exposure, thresholds deviate little from the $\Delta I$ vs $I$ curve for equilibrium. The greatest increment amounts to only $0.4 \log$ unit, as compared to $1.25 \mathrm{log}$ unit in the pre-exposed eye.

When the background luminance prevailing at any moment during the course of dark adaptation is temporarily turned off, thresholds measured shortly thereafter are considerably lowered, but they are still an average of 2 times (for 14-min change) to 3 times (for 21-min change) higher than those found during normal dark adaptation (Fig. 3). Several consecutive dark thresholds taken within such intervals of temporary background removal are uniformly elevated and do not seem to approach the standard curve recorded during undisturbed adaptation in darkness.

\section{DISCUSSION}

Time courses for increment thresholds, determined against a waning background, lag behind the regular dark-adaptation curve obtained without background illumination. The difference between both types of thresholds is predominately influenced by two factors, level and duration of pre-exposure and rate of background change. Only the latter variable was investigated in this study. When steeply decreasing field luminances are used, delays are restricted to the first few minutes of dark adaptation after extinction of the pre-exposure 
light. For backgrounds with gentler slopes, thresholds are elevated in value or delayed in time throughout the entire curve.

Results suggest that a linear rate of decrease of log background luminance does not necessarily produce a linear log-threshold-vi-time curve. Even though the rapid phase of instartaneous adaptation is straightened out, a discontinuity at about the same luminance level as the cone-rod transition in the $\Delta I$ vs $I$ curve is not always eliminated. A kink associated with the normal dark-adaptation curve would also be expected to remain if it were sufficiently marked. Our data do not indicate whether the levels of the increment-threshold and darkadaptation breaks that usually coincide are affected when recovery from bleaching occurs in the presence of a changing adapting field.

Increment thresholds upon transient backgrounds are higher than those determined against fixed levels of equal luminance. This holds notably for high rates of background change and at low luminances, i.e, for conditions urder which the time course oi increment thresholds in Fig. 1 deviates least from that of normal dark thresholds. In turn, curves with great temporal delays during dark adaptation yield only small increases of increment threshold. The difference between thresholds for dynamic and stationary backgrounds should disappear entirely when the adapting luminance changes sufficiently slowly for recovery to reach equilibrium.

A comparison of threshold elevations found with and without pre-exposure (3.5-min background) suggests that most of the increment has to be attributed to pigment bleaching, although less than $6 \%$ rhodopsin was affected by the initial illumination. To account for the inverse relationship between the threshold elevation and the interval separating pre-exposure and measurement, increment thresholds in the lower-right half of Fig. 2 were replotted. First, the aftereffect of the preexposure was calculated by finding for each dark threshold (Fig. 1, $\mathbf{x}$ ) the corresponding equivalent background luminance in the $\Delta I$ vs $I$ curve for steady state. ${ }^{1,2}$ In two instances, dark thresholds measured while the background was temporarily turned off (Fig. 3 , circles and diamonds) were substituted in the calculation to include the aftereffect of the waning background. A last and final correction was made for the Eigenlicht. This dark light of the retina is given by the intersection of the two broken lines that are tangential to the increment-threshold curve for steady state in Fig. 2. To incorporate the Eigenlich, its value has to be added in each case. This may be done by simply using the extrapolated continuation, instead of the curve itself, for translating dark thresholds into equivalent background Juminances, Increment thresholds obtaired without pre-exposure (filled squares) were corrected only for Eigenlicht.

The sum of the equivalent background obtained in this manner and the real background at any time during dark adaptation represents the total effective background. Because actual luminance decreased faster than equivalent luminance, real backgrounds that reached their minima soon after pre-exposure should be affected most by the correction. This expectation is confirmed by adapting nelds from $0.3 \mathrm{~mL}$ downward. If plotted against the logarithm of their revised adapting luminances, increment thresholds are shifted to the left and data points are brought within close proximity of the $\Delta I$ vs $I$ function for steady state (inset). A remaining difference of about $0.15 \mathrm{log}$ unit throughout the entire curve may indicate a constant experimental error. This near coincidence lends support to the Blakemore and Rushton $^{8}$ concept of linear additivity of real and equivalent backgrounds and extends it to ratios ranging from 1000: 1 to $1: 1000$.

External backgrounds, by adding to equivalent or internal backgrounds, are believed to raise the increment threshold through a Ieduction of the signal-to-noise ratio ${ }^{19}$ in the receptor pool..$^{820.21}$ However, to some extent they also seen to affoct the sensinivity of the receptors directly. The increase of dark thresholds measured after removal of a transient luminance over those recorded during regular dark adaptation (Fig. 3) can be explained only by the prolonged exposure to the waning background. The extent of the threshold increase may depend on the combined effects of duration and luminance of the preceding illumination. Uncertain is whether the observed increments are caused passively by a delayed recovery from the pre-exposure light or actively by rebleaching.

Because the waning adapting fields in our experiment were fairly weak, a neural rather than a photochemical explanation of these data appears to be indicated. Yet, dark thresholds measured consecutively during the same period of intermittent background extinction or after the background luminance had been set at zero (Fig. 1, arrows) do not exbibit the rapid gain characteristic for neural recovery. ${ }^{6}$ Instead, they resemble longerlasting threshold elevations found in the dark-adapted eye after temporary exposure to low photopic luminance levels. $^{22}$ Unless a slow process of neuronal reorganization ${ }^{23}$ accounts for our results, they may be tentatively interpreted as genuine retardations of dark adaptation. Future study of pigment regeneration in the presence of waning adapting fields is necessary to investigate the nature and origin of these delays.

Is adaptation in the presence of a waning background delayed behind its potential rate? Our data indicate that the eye approaches optimum performance for light discrimination when the adapting luminance decreases at a rate not exceeding $1 \log$ unit in $3 \mathrm{~min}$. Under such conditions, the time course of increment thresholds is significantly prolonged and accompanied by an eleva. tion of dark thresholds. These relationships ought to be valid also for slower transitions from light to dark, such as those occurring during twilight and dusk. 


\section{ACKNOWLEDGMENTS}

Dr. E. Wolf provided financial support, laboratory space, and equipment. G. Gambone of Northeastern University compiled astronomical data from the Blue Hills Observatory, MiIton, Mass. Dr. W. Richards and Dr. H.-L. Teuber critically read the manuscript.

\section{REFERENCES}

* This work was supported (in part) by PHS Center Grant NB-05691 and by PHS Grant NB-01482 from the National Institute of Neurological Diseases and Blindness.

$\dagger$ ATN and CDB worked under the undergraduate cooperativeeducation program of Northeastern University.

† Address reprint requests to Ophthalmic Library, Retina Foundation, 100 Charles River Plaza, Boston, Mass. 02114.

1 B. H. Crawford, Proc. Roy. Soc. (London) B123, 69 (1937).

2 B. H. Crawford, Proc. Roy. Soc. (London) B134, 283 (1947).

${ }^{3}$ L. L. Sloan, Am. J. Ophthaimol. 33, 1077 (1950).

${ }^{4}$ M. J. Zigler, E. Wolf, and E. S. King, J. Opt. Soc. Am. 41, 354 (1951).

${ }^{5}$ R. G. Hattwick, J. Opt. Soc. Am. 44, 223 (1954).

${ }^{6}$ H. D. Baker, M. D. Doran, and K. E. Miller, J. Opt. Soc, Am. 49, 1065 (1959).

7 W. A. H. Rushton, J. Physiol. (London) 156, 193 (1961).

${ }^{B}$ C. B. Blakemore and W. A. H. Rushton, J. Physiol. (London) $181,629(1965)$.
${ }^{9}$ L. K. Allen and K. M. Dallenbach, Am. J. Psychol. 51, 540 (1938)

${ }^{10}$ E. A. Suchman and H. P. Weld, Am. J. Psychol 51, 717 (1938).

11 D. A. Grant and F. A. Mote, J. Exptl. Psychol. 39, 610 (1949).

${ }^{12}$ R. D. Gunkel and H. Bornschein, Arch. Ophthalmol. 57, 681 (1957).

${ }^{13}$ E. J. Sweeney, J. Opt. Soc. Am. 49, 667 (1959).

14 E. Wolf, in Flash Blindness Symposium, Procedings, edited by J. M. Davies and D. T. Randolph (U. S. Army Natick Laboratories, Armed Forces, National Research Council, Committee on Vision, Washington, D. C., 1967), p. 6.

${ }^{15} \mathrm{~J}$. G. Beebe-Center, L. Curmichael, and L. C. Mead, Aeronaut. Eng. Rev. 3, 9 (1944).

${ }^{16} \mathrm{~K}$. Bullich, Ber. Deutsch. Wetterdienst. (CS-Zone) 4, 2 (1948).

17 M. J. Allen and J. H. Carter, J. Am. Optom. Assoc. 35, 25 (1964).

18 W. J. Crozier and A. H. Holway, J. Gen. Physiol. 22, 341 (1939).

${ }^{19} \mathrm{H}$. B. Barlow, Vision Res, 4, 47 (1964).

$\approx$ W. A. H. Rushton, J. Physiol. (London) 178, 141 (1965),

${ }^{21} \mathrm{~J} . \mathrm{J}$. DuCroz and W. A. H. Rushton, J. Physiol. (London) 183,481 (1966).

2 S. M. Luria and J. A. S. Kinney, U. S. Naval Med. Res. Lab., Groton, Conn., Rep. No. 347, 20, I (1961).

${ }^{23}$ H. B. Barlow, R. FitzHugh, and S. W. Kuffer, J. Physiol. (London) 137, 338 (1957).

\section{Technical Council}

Charles J. Koesmer (Chaiman), Research Laboratery. Anerican Optical Corporation, F. O. Boz 187, Framingham Centre, Mass, 01701

ROBERT V. POLE (Vice Chairman), IBM Corporation, Nonterey \& Cottle Roads, San Jose, California 95114

The chaimen of the Technical Groups comprise (ex officio) the Technical Coustil.

Aeronautics and Space Optics-RAYMond H. WiTCFE McDonnelł Douglas Astronautics Co., 5301 Bolsa Ave., Huntington Beach, Calif. 92647

Atmospheric Optics-Freeman F. HALL, JR.

NOAA, Wave Fropagation Laboratory, Environmental Research Labs, Boulder, Colo. 80302

Color-C. J. BARTLESON

Kollmorgen Corporation, Box 950, Newburgh, N. Y. 12550

Information Pracessing, Holography, \& CoherenceJOSEPH W. GOODMAN

Stanford Electronics Laboratories, Stanford, Calif. 94305

Lasers-ANTHONY J. DEMTARIA

United Aircraft Research Laboratories, Enst Hartford, Conn. 06108
Lens Design-DArid S. Grey

David Grey Associates, 60 Hickory Drive, Waltham, Mass. 02154

Optical Materials-Beswetr Sherman

General Telephone and Electronics Laboratories, 208-20 Willets Point Blvd., Elushing, N. Y. 11360

Radiometry and Photometry-HENRY J. KosTkowskI National Bureau of Standards, Washington, D. C. 20234

Raman-ElLis P. LiPPINCOTT

Dept. of Chemistry, University of Maryland, College Park, Md. 20740

Spectroscopy-Ross A. McF ARLANE

School of Electrical Engineering, Cornell University, Ithaca, N. Y. 14850

Thin Films and InterferometryPHILIP W. BAUMeIsTER

Institute of Optics, University of Rochester, Rochester, N. Y. 14627

Vision-Lorrin A. RigGs

Hunter Laboratory, Brown University, Providence, R. I. 02912 